\title{
Environmental Investment Decision of Green Supply Chain considering the Green Uncertainty
}

\author{
Shaobo Wu, ${ }^{1}$ Xun Yao, ${ }^{1}$ and Guangdong Wu $\mathbb{D}^{2}$ \\ ${ }^{1}$ Business School, Southwest University for Nationalities, Chengdu 610041, China \\ ${ }^{2}$ School of Public Affairs, Chongqing University, Chongqing 400044, China \\ Correspondence should be addressed to Guangdong Wu; gd198410@126.com
}

Received 17 September 2020; Revised 2 October 2020; Accepted 12 October 2020; Published 4 November 2020

Academic Editor: Wei Zhang

Copyright (c) 2020 Shaobo Wu et al. This is an open access article distributed under the Creative Commons Attribution License, which permits unrestricted use, distribution, and reproduction in any medium, provided the original work is properly cited.

\begin{abstract}
The uncertainty of eco-friendly intermediate components has an important impact on green supply chain decisions. In this paper, the Stackelberg game model of green investment decision-making among enterprises is established by considering the case of the supplier's green investment alone and the case of the manufacturer and the supplier's joint green investment. The influence of green uncertainty on enterprise's decision-making is analyzed, and the green investment decision-making strategies of both sides in two cases are compared. There are four main conclusions derived from the results: (i) with the increase in the supplier's green cost coefficient, the supplier will reduce the green investment and the manufacturer will reduce the share of the green costs; (ii) with a decrease in uncertainty for eco-friendly intermediate components and the increase in their feasibility factor, the supplier will increase the greenness of intermediate components and increase the investment in environment, and the manufacturer will reduce the share of the green costs; (iii) the increase in the manufacturer's share of green costs will promote the supplier to increase the greenness of intermediate components and increase its green investment, which shall increase the supplier's optional choice space of for green investment; (iv) in the case of the manufacturer and the supplier jointly making a green investment, the threshold value for the environmental input of the supply chain members (i.e., the manufacturer and the supplier) is lower, and the supply chain members will have more choice space. At the same time, the care for environment in the case of a cooperative is higher than that in the case of a supplier investing alone.
\end{abstract}

\section{Introduction}

With the development of economy, the manufacturing industry has been developing rapidly. The rapid development of manufacturing industry provides abundant choice of products to humans, and it also leads to many environmental problems such as resource depletion and environmental pollution. Since the industrial era, the energy consumption is too high, the resource consumption is excessive, the industrial wastes emissions are excessive, the ecological environment is deteriorating, and the sustainability of economy and social development is seriously restricted [1]. Due to the increasingly prominent global environmental problems, sustainable development has been widely accepted. Green supply chain considers resource consumption and has been paying more attention to environmental impact. Therefore, more and more enterprises have begun to produce "green" products and implement green supply chain management in practice [2].

In practice, the Canon Group issued the "Global Canon Green Procurement Standards" in 1997, which has been promoting green purchasing activities for 20 years. Compliance with the green procurement standard is listed as one of the basic requirements and is an important condition for starting and continuing business transaction. Canon believes that not only they should comply with environmental regulations but that all suppliers should comply with them. Therefore, the standard book reflects the global environmental regulations and industry standards. Canon's production outlets in China strictly abide by the national and local environmental regulations, such as cleaner production and discharge standards and sound waste water and waste 
gas treatment facilities. For instance, the self-discharge standard for wastewater is $20 \%$ lower than that of environmental laws and regulations, so as to ensure that the actual discharge will not exceed the standard. In addition, Canon pays attention to technological innovation, carries out energy-saving transformation of equipment, selects energy-saving equipment within the scope of technology and economy, strives to improve their energy utilization rate, and actively uses renewable energy [3]. Similarly, the Lenovo Group not only abides by the Code of Conduct of the Electronic Industry Citizenship Coalition (EICC) and all applicable rules but also pays attention to energy consumption in the production process. They reduce emissions in general by reducing carbon emissions in business activities, increasing the use of renewable energy and strengthening the development and promotion of green technologies. Lenovo's purchasing department has standardized procedures covering a wide range of areas and has developed a comprehensive code of conduct for suppliers. Lenovo takes into account suppliers' environmental performance, such as compliance and emission reduction of hazardous substances, use of recycled materials after environmental protection consumption, transparency and emission reduction of greenhouse gas emissions, and avoidance of conflict minerals [4].

However, the process of making a green supply chain is a process of technology transformation, which requires the participation of upstream and downstream of a supply chain and often faces uncertainties. The reality also shows that most of the technology transforming products fails to enter the market, with this failure rate being between $25 \%$ and $45 \%$. A study has shown that, out of every seven new product ideas, four products enter the development stage, one-pointfive products enter the market, and only one is successful [5]. The uncertainty of green products in supply chain comes from two main aspects: first, the technological uncertainty of green products. Although some ideas about green development of products are technically attractive and feasible at first, many technological problems cannot be solved once they are implemented. The dilemma is whether the new product function brought by green technology is really what consumers want, or the new technology cannot be further improved due to the lack of sustainable development skills of enterprises. Second, the market uncertainty of green products is an aspect that bifurcates into three segments: market demand, scale of demand, and market growth rate. The uncertainty of the market means that the enterprise does not know enough about the market. The failure of green development for many products is not due to technology defects but due to mistakes in market decision-making. It is beyond doubt that a new green product needs a potential market to succeed. Therefore, before beginning the green development of a product, it is necessary to conduct a full market analysis. Although market analysis can help enterprises in making green product development plans, they are still not aware whether they have obtained accurate customer demand information. Subsequently, there is the uncertainty of market scale. For instance, even when market demand for green products appears, the scale of this market demand cannot be predicted, which leads to wrong production and marketing strategies. Lastly, due to the uncertainty of market growth rate, it is difficult for enterprises to predict when and how fast the market will grow in the introduction stage of the green product's life cycle. If the growth period and the maturity period are shorter than expected, they may not be able to obtain the supposed profits or even experience losses on green projects. For the reasons above, supply chains should have uncertainty in mind when considering green products.

The main purpose of this paper is to analyze the impact of uncertainty of green products on decision for environmental investment in supply chain. For the purposes of our analysis, we consider a supply chain consisting of one manufacturer and one supplier. A Stackelberg game model of green investment decision-making among enterprises was established. In this model, we introduce green uncertainty factors, analyze the impact of green uncertainty on enterprise decision-making, and compare the green investment decision-making strategies of both sides in two cases. We analyze the two cases when only the supplier is "green" and the case where the manufacture's and the supplier's cooperative is "green". The specific research questions of this paper include the following: (i) what is the impact of supplier's green costs coefficient on the manufacturer's share of green cost and the supplier's input? (ii) What is the impact of product uncertainty on product greenness and green investment of the manufacturer and the supplier? (iii) What is the impact of the manufacturer's share of green cost on product greenness and the supplier's choice space?

The main contribution of this paper is twofold: (i) we consider the impact of green uncertainty in the green supply chain model by introducing the green feasibility factor and alternative choice space to analyze the cooperation of all members in the supply chain; (ii) we analyze the impact of green uncertainty on the environmental input in the supply chain by establishing a multistage game-theoretical model considering the case of the supplier's green investment alone and the case of the manufacturer and the supplier's joint green investment.

The rest of this paper is organized as follows: Section 2 provides the literature review. Section 3 is to establish basic model. Section 4 is to analyze the green decision for the supplier alone. Section 5 is to analyze the green decision of the manufacturer and the supplier's cooperative. Section 6 is to analyze a numerical example. Sections 7 and 8 , provide results and draw conclusions.

\section{Literature Review}

The concept of green supply chain was first proposed by the manufacturing research association of Michigan State University in 1996. The green supply chain (GSC) is defined as a kind of modern management that considers environmental impact and resource efficiency in the whole supply chain [6]. Green supply chain management includes green material management, green product production management, and green product sales management [7]. 
This research is closely related to the coordination and decision-making of the green supply chain. There are several researches about it in recent years. Barari et al. use an evolutionary game approach to discuss the sales of green and non-green products by two manufacturers in dual distribution channels [8]. Cao and Zhang coordinate a green channel between providers and manufacturers with a pricing strategy [9]. Hafezalkotob develops a price competition model between a green and a regular supply chain, both under the influence of government financial intervention, where the effects of government's tariffs on the actors' optimal strategies are analyzed. It was found that there are specific boundaries for tariffs, which guarantee a stable and competitive market [10]. Aydin et al. study the coordination between a supplier and other actors to design a production line in a closed-loop supply chain. They use the Stackelberg game to analyze a multiobjective optimization model for the production line, which includes new and remanufactured products [11]. Yang and Xiao study the optimal price and "greenness" of a product in a green supply chain under government intervention [12]. Zhu and $\mathrm{He}$ use a gametheory approach to investigate pricing competition and the degree of competition among green products in different structures of the supply chain [13].

In recent years, the literature is abundant with papers regarding the topics of supply chain and environment protection. Jamali and Barzoki investigate the decision on pricing for two substitute products, a green product produced by one manufacturer, and a non-green product produced by the other one, under two dual-channel supply chains including retail and Internet channels [14]. Taleizadeh et al. use Nash and Stackelberg games to investigate the coordinated contracts in a two-echelon green supply chain considering pricing strategy [15]. Modak et al. investigate a revenue-sharing contract in a two-echelon supply chain consisting of one retailer and one manufacturer, considering trade regulation to control carbon emission [16]. Hong and Guo investigate coordination contracts in a two-echelon supply chain considering consumer environmental awareness, where the coordination contracts include a two-part tariff, cost sharing, and price contracts [17]. Cao and Yu study coordinated contracts in a two-echelon supply chain by considering cap-and-trade regulation to reduce the amount of carbon, where they find that the coordinated contracts include revenue sharing, buyback, and quantity discount forms [18]. Song and Gao discuss the impact of two revenue-sharing models on green supply chain's product greening levels, prices, and profit considering consumer sensitivity [19]. Dey and Saha discuss the joint impact of the retailer's strategic decision and consumer's continuous expectation on the investment and wholesale pricing decision of the manufacturer when it comes to improving the greening level of the product in a green supply chain [20]. Liu and Xiao investigate the decisions on price and collection rate and reverse channel structure strategy of a dyadic closed-loop supply chain with corporate social responsibility and green consumers, within which the manufacturer and green consumers exhibit environmental responsibility behaviors [21]. Nielsen et al. explore the repercussions of a dominant intermediary in a three-echelon green supply chain considering price and greening level sensitive demand [22]. Murali et al. study green product development among competing firms considering the impact of voluntary ecolabels and mandatory environmental regulation [23]. Luo et al. study the optimal procurement decision in a two-echelon green supply chain with options under capital constraints and financing credit support [24]. Kang et al. investigate the member's efforts to reduce pollution in the green supply chain considering the Green Credit Policy [25]. Zhang et al. investigate green supply chain decision-making under different government policies [26]. Yuan et al. examine different government subsidy strategies in green supply chain management based on dynamic game theory and the principal-agent theory [27]. Shahzad et al. identify the influence of organizational compatibilities on green supply chain management (GSCM) efforts and estimate their influence on organizational performance [28]. Pakseresht et al. deal with Green Product Families (GPFs), which are produced based on the Assemble-to-Order (ATO) approach in order to cover diverse customer needs. They design GPFs with Stackelberg game toward a sustainable optimal selection of green components, modules, and product variants [29]. Wang et al. study the competitive and sustainable supply chain network design problem by considering the chain-to-chain competition between two supply chains [30]. Zhang et al. compare the optimal green decisions and profits under single-channel or dual-channel strategies with and without green investment [31]. Wang et al. study the decisions and coordination of green e-commerce supply chain under green manufactures' fairness concerns considering the product green degree and the e-commerce platform's service [32]. Wu et al. investigate the coordination of store brand product's green supply chain based on negotiation [33]. Ghomi-Avili et al. propose a robust bilevel model of the single-product multiperiod network design problem for a competitive green supply chain considering pricing and inventory decisions under uncertainty and disruption risks [34].

Some of these papers discuss coordination and decisionmaking of green supply chain. For example, Shahzad et al. identify the influence of organizational compatibilities on green supply chain management (GSCM) efforts [28]; Wang et al. investigate the decisions of green e-commerce supply chain under green manufactures' fairness concerns, albeit in neither of them is the impact of green uncertainty on decision-making of green supply chain's environment has not been investigated [30]. This paper attempts to cover this gap by proposing a Stackelberg game model and analyzing its influence on decision-making. In this paper, the green uncertainty factor is added into the environmental investment decision in a green supply chain. It is found that this uncertainty factor has an important impact on the environmental investment. With the green uncertainty of intermediate components decreases and the green feasibility factor increases, the supplier will increase the greenness of intermediate components and increase the green investment, and the manufacturer will reduce the share of green costs. 


\section{Modelling}

In order to facilitate this study, we make the following assumptions:

(i) A green supply chain is composed of one supplier and one manufacturer, deemed as a two-echelon supply chain.

(ii) The market demand function of the product is $p=a-q$, where $p$ is the price of the final product, $a$ is the market capacity and is a constant greater than zero, and $q$ is the sales volume of the final product and $q \geq 0$. The price of the intermediate components sold by the supplier to the manufacturer is $w$, the cost of the final product of the manufacturer is $c_{1}$, and the cost of the intermediate component produced by the supplier is $c_{2}$, where $a>c_{1}+c_{2}$. Therefore, the profit functions of the two actors, the supplier, and the manufacturer are as follows:

$$
\begin{aligned}
& \prod_{s}=q\left(w-c_{2}\right), \\
& \prod_{m}=q\left(p-w-c_{1}\right) .
\end{aligned}
$$

(iii) In the green supply chain, the benefits brought by the green investment of intermediate components can be shown as follows: reducing the environmental management costs, recycling costs, or rework costs caused by unqualified quality. In short, the production cost of green materials can be reduced. We assume that the greenness of an intermediate component is $e_{\text {, where }} e \geq 0$, which translates into a decrease in the production cost of intermediate components. After the supplier's green technology innovation, the unit production cost of green materials is $\left(c_{2}-e\right)$. The cost function of the supplier's green investment is a quadratic function, and the cost is $(1 / 2) \mu e^{2}$, where $\mu$ is the cost coefficient of the supplier's greenness. Accordingly, the revenue functions of the supplier and the manufacturer are as follows:

$$
\begin{aligned}
& \prod_{s}=q\left(w-c_{2}+e\right)-\frac{1}{2} \mu e^{2}, \\
& \prod_{m}=q\left(p-w-c_{1}\right),
\end{aligned}
$$

Although equations (2) and (3) are the same in form, the price of green materials in equation (3) is bound to decrease due to the influence of green input by the supplier, thus increasing the income of the manufacturer in equation (3).

(iv) As mentioned above, the green input of the supplier can reduce the price of products, and for manufacturers, the supply price of intermediate components can be reduced. If the manufacturer wants to obtain a lower supply price of intermediate components, the supplier needs to increase the green investment. However, the supplier may not be able to meet the requirements of the manufacturer for any reason. For example, the supplier may be limited in funds or hesitant to increase investment in technology innovation due to the uncertainty of green products. Therefore, if the manufacturer wishes to obtain a lower price $w$ of green materials, they would need to subsidize the green costs of the supplier. This way, the price of the product is reduced through a green cooperative. When we assume that the manufacturer's share of the green investment is $t(0<t<1)$, the revenue functions of the green supplier and the manufacturer in a cooperative are as follows:

$$
\begin{aligned}
& \prod_{s}=q\left(w-c_{2}+e\right)-\frac{1}{2}(1-t) \mu e^{2}, \\
& \prod_{m}=q\left(p-w-c_{1}\right)-\frac{1}{2} t \mu e^{2} .
\end{aligned}
$$

(v) The results of a green investment in intermediate components are uncertain and do not necessarily bring benefits. This uncertainty has an important impact on the performance of a green supply chain and green investment. In the result, we should consider the impact of the uncertainty of green intermediate components in the model. The green uncertainty includes technological uncertainty and economic uncertainty. On the one hand, technological uncertainty occurs due to the rapid technological changes in modern society. This uncertainty leads to the uncertainties of the product's R\&D cycle, investment, and product's success rate. Sometimes, even if the technology is at the cutting-edge, it may not be feasible or desirable. On the other hand, economic uncertainty runs through the whole process of the product's green innovation. It is especially caused by factors such as product positioning, market selection, promotion methods, and marketing opportunity. These factors make it more difficult to evaluate the benefits of green technology innovation.

The symbols used in this study are summarized in Table 1.

Because of the uncertainty of investment in green technology, the green supply chain should consider whether the green technology is feasible and what be the probabilities of achieving the expected return on the innovation when making the decision of investing in environmental components. We assume that, under the external conditions, the green feasibility factor is $\theta$, the greenness of components $e$ is actually the target performance of the product cost reduction, and the actual innovation performance of green is $e+\varepsilon$, 
TABLE 1: Introduction of the symbol.

\begin{tabular}{lc}
\hline Symbol & Symbolic meaning \\
\hline$p$ & Price of the final product \\
$q$ & Market capacity \\
$w$ & The price of the intermediate components sold by the supplier to the manufacturer \\
$c_{1}$ & The cost of the final product of the manufacturer \\
$c_{2}$ & The cost of the intermediate component produced by the supplier \\
$\prod_{s}$ & The profit of the supplier \\
$\prod_{m}$ & The profit of the manufacturer \\
$\mu$ & The greenness of the intermediate component \\
$t$ & The cost coefficient of the supplier's greenness \\
\hline
\end{tabular}

where $e$ is the determined target innovation performance, $\varepsilon$ represents the deviation between the objective innovation performance and the actual innovation performance of the green supply chain and follows the normal distribution $N\left(0, \sigma^{2}\right)[35-37]$. The uncertainty of a green investment will affect the decision-making, which shall be considered in Sections 4 and 5 .

\section{Green Investment Decision-Making: Case of a Single Supplier}

In the case of the supplier's single green investment, the supplier first determines the greenness $e$ of the intermediate component. If the green product is successful, the supplier asks the manufacturer for the price $w$ of the intermediate component. According to the price of the component, the manufacturer determines the output $q$ and price $p$ of the final product. The decision-making sequence of this green supply chain is shown in Figure 1.

By the first-order condition of the manufacturer's profit function in equation (3), we can get the output decision of the manufacturer's final product as follows:

$$
q(w)=\frac{1}{2}\left(a-w-c_{1}\right)
$$

It can be seen from equation (6) that the supply price of intermediate components will affect the manufacturer's choice of output. By substituting formula (6) into equation (2), the supplier's revenue function is transformed into

$$
\prod_{s}=\frac{\left(a-w-c_{1}\right)\left(w-c_{2}+e\right)-\mu e^{2}}{2} .
$$

Let $\left(\partial \prod_{s} / \partial w\right)=0$ in equation (7), the optimal demand price $w$ of intermediate components can be obtained by a first-order derivation:

$$
w(e)=\frac{a-c_{1}+c_{2}-e}{2} .
$$

Substituting equation (8) into equation (7), we can get the supplier's revenue function:

$$
\prod_{s}(e)=\frac{\left(a-c_{1}-c_{2}+e\right)^{2}}{8}-\frac{1}{2} \mu e^{2} .
$$

It is worth noting that equation (9) is the profit obtained by the supplier when the green investment in intermediate components is successful. The uncertainty in the process of making a green investment in the component is not considered. Without considering the uncertainty of the green investment, the gross profit of the supplier (i.e., the profit before deducting the cost) is $\left(a-c_{1}-c_{2}+e\right)^{2} / 8$. If we consider the impact of uncertainty of the intermediate component's green input, the actual performance brought by the green input $e$ is $e+\varepsilon$.

If the supplier's green feasibility factor is $\theta$ and the expected gross profit is discounted by this feasibility factor $\theta$, then under the uncertainty of the green input, the expected return of the supplier is $\prod_{s}(e)=E\left[\theta \bullet\left(\left(a-c_{1}-c_{2}+e+\varepsilon\right)^{2} / 8\right)\right]-(1 / 2) \mu e^{2}[38,39]$. After further simplification, the equation can be obtained as

$$
\prod_{s}(e)=\theta \bullet \frac{\left(a-c_{1}-c_{2}+e\right)^{2}}{8}-\frac{1}{2} \mu e^{2},
$$

where the first derivative of $e$ is performed, let $\partial \prod_{s}(e) / \partial e=0$, and we can get the optimal green level of the supplier considering the uncertainty of the green input as follows:

$$
e *_{s}=\frac{\theta\left(a-c_{1}-c_{2}\right)}{4 \mu-\theta} .
$$

By observing equation (11), we can induct the first proposition of this paper:

Proposition 1. In the case of a single supplier's green investment, the following is observed:

(i) The optimal green input level of the supplier decreases with the increase in the cost coefficient and increases with the increase in the green feasibility factor

(ii) Only when the technological feasibility factor is higher than a certain threshold value can the supplier carry out the green investment

Proof. firstly, because $\left(\partial e *{ }_{s} / \partial \mu\right)=\left(-4 \theta\left(a-c_{1}-c_{2}\right) /\right.$ $\left.(4 \mu-\theta)^{2}\right), a>c_{1}+c_{2}$, it is easy to prove $\left(\partial e *{ }_{s} / \partial \mu\right)<0$, since it means that the optimal green level of the supplier $e *_{s}$ is a decreasing function of the input cost coefficient $\mu$. 


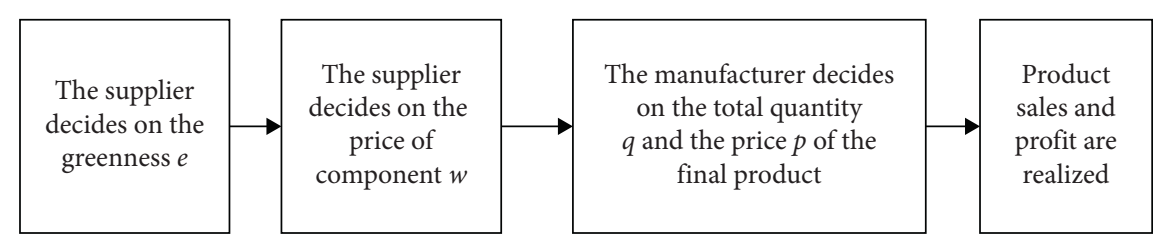

FIgURE 1: Sequence diagram of the supplier's decision single green investment.

Secondly, because $\left(\partial e *_{s} / \partial \theta\right)=\left(4 \mu\left(a-c_{1}-c_{2}\right) /\right.$ $\left.(4 \mu-\theta)^{2}\right), a>c_{1}+c_{2}$, it is easy to prove that $\left(\partial e *{ }_{s} / \partial \theta\right)>0$, which means that the optimal green input level of the supplier $e *{ }_{s}$ is an increasing function of the green feasibility factor $\theta$.

It is easy to understand, that with the increase in the input cost coefficient, the cost of the green investment of the supplier will increase, thus reducing the supplier's investment enthusiasm. With the improvement of the technological feasibility of the green product, the supplier faces less technological uncertainty in the process of a green investment. In return, this can reduce the possibility of failure of the green product and increase the supplier's enthusiasm to increase the green investment.

Finally, in the case when the supplier does not make the green investment, the model can be written as $e=0$. At this time, there is no uncertainty about the greenness of the component, that is, the feasibility of green products is $\theta=1$, so the supplier's revenue is $\prod_{s}^{N}=\left(\left(a-c_{1}-c_{2}\right)^{2} / 8\right)$. When the green product is uncertain, only when the profit of green investment is greater than that of no green investment, the supplier will make the green investment, that is, the condition $\prod_{s}(e) \geq \prod_{s}^{N}$ must be met. In other words, the following inequality must be satisfied:

$$
\theta \bullet \frac{\left(a-c_{1}-c_{2}+e\right)^{2}}{8}-\frac{1}{2} \mu e^{2} \geq \frac{\left(a-c_{1}-c_{2}\right)^{2}}{8} .
$$

By substituting the supplier's optimal green level $e_{s} *$ in equation (11) into inequality (12), we can get the inequality as follows:

$$
\begin{aligned}
\theta \bullet & \frac{\left[a-c_{1}-c_{2}+\left(\theta\left(a-c_{1}-c_{2}\right) / 4 \mu-\theta\right)\right]^{2}}{8} \\
& -\frac{1}{2} \mu\left[\frac{\theta\left(a-c_{1}-c_{2}\right)}{4 \mu-\theta}\right]^{2} \geq \frac{\left(a-c_{1}-c_{2}\right)^{2}}{8} .
\end{aligned}
$$

By solving inequality (13) and simplifying it, we can get the following result:

$$
\theta \geq \frac{4 \mu}{4 \mu+1}
$$

Let $\xi=(4 \mu /(4 \mu+1))$, where $\xi$ is the threshold value of the supplier's green investment when the product is in the case of the single supplier. Only when the green feasibility factor $\theta \geq \xi$ exists, the supplier's green investment in the product will occur.

It shows that the supplier should consider the uncertainty of a green investment when it invests in green products. When the green feasibility factor is in the range
$[4 \mu /(4 \mu+1), 1]$, the supplier will choose to invest. The larger the feasibility threshold $\xi=(4 \mu /(4 \mu+1))$ is, the smaller is the choice space of the green investment. The smaller the feasibility threshold $\xi=(4 \mu /(4 \mu+1))$ is, the larger is the choice space for the green investment of the supplier.

Besides, because $(\partial \xi / \partial \mu)>0$, the feasibility threshold value of the supplier's green investment increases with the increase in the cost coefficient. Understandably, if the cost of the supplier's green investment increases, it will reduce the enthusiasm of the supplier for the green investment and shall reduce the scope of the suppliers' choices.

\section{Green Investment Decision-Making: Case of a Cooperative between the Supplier and the Manufacturer}

When the manufacturer and the supplier jointly invest in a green intermediate component, the manufacturer, as the leader, first determines the share of green cost $t$. As a follower, the supplier decides the green level $e$ of the intermediate component according to the manufacturer's cost share. The supplier then asks the manufacturer for the price $w$ of the intermediate component. At last, the manufacturer determines the output and price of the final product according to the price of the intermediate component. The decision-making sequence of a green supply chain in the case of green cooperative is shown in Figure 2.

We use the inverse method to solve the problem. According to the first-order condition of the profit function in equation (5), we can get the output decision of the manufacturer's end product as follows:

$$
q(w)=\frac{1}{2}\left(a-w-c_{1}\right) .
$$

Substituting equation (15) into the supplier's revenue function of equation (4), it can be transformed into as follows:

$$
\prod_{s}(w, e)=\frac{1}{2}\left(a-w-c_{1}\right)\left(w-c_{2}+e\right)-\frac{1}{2}(1-t) \mu e^{2} .
$$

We take the derivative of $w$ in equation (16). Let $\left(\partial \prod_{s}(w, e) / \partial w\right)=0$, we can obtain the optimal price of the intermediate component:

$$
w(e)=\frac{a-c_{1}+c_{2}-e}{2} .
$$

Substituting equation (17) into equation (16), the supplier's revenue function can be rewritten as follows: 


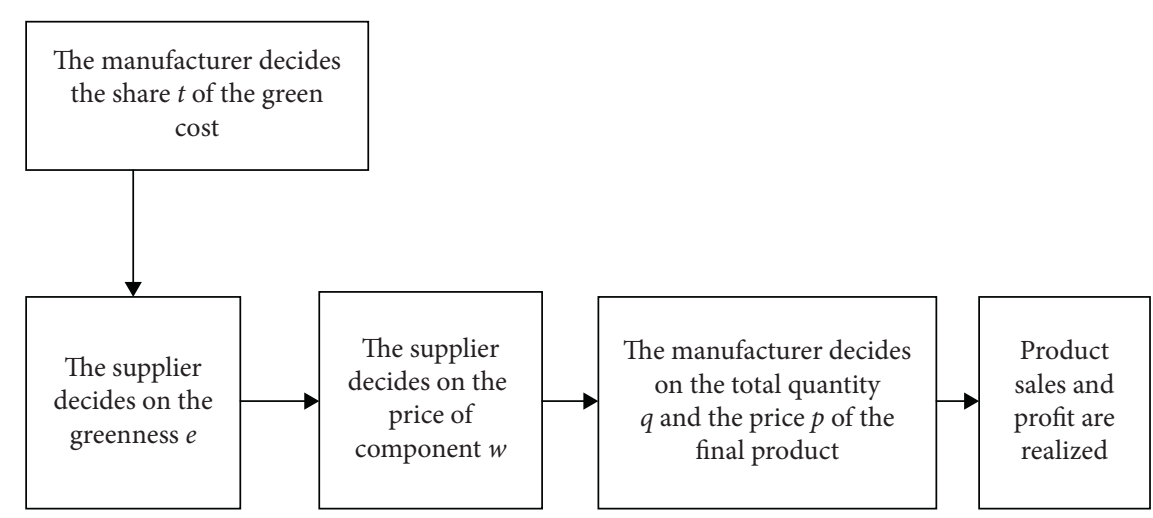

FIgURE 2: Decision sequence diagram of green supply chain under cooperative green.

$$
\prod_{s}(e)=\frac{\left(a-c_{1}-c_{2}+e\right)^{2}}{8}-\frac{1}{2}(1-t) \mu e^{2} .
$$

We add the uncertainty factor of the green product to equation (18) and the expected revenue function of the supplier is changed into

$$
\prod_{s}(e)=\theta \bullet \frac{\left(a-c_{1}-c_{2}+e\right)^{2}}{8}-\frac{1}{2}(1-t) \mu e^{2} .
$$

We take the derivative of $e$ in equation (16). Let $\left(\partial \prod_{s}(e) / \partial e\right)=0$, we can get the optimal green level of the supplier under the condition of considering the uncertain factor of greenness as follows:

$$
e_{C}^{*}=\frac{\theta\left(a-c_{1}-c_{2}\right)}{4(1-t) \mu-\theta}
$$

We note that $e_{C}^{*}$ must satisfy the condition $e_{C}^{*}>0$, because we have the assumption that $a>c_{1}+c_{2}, 4(1-t) \mu-$ $\theta>0$ must be satisfied in equation (20). In equation (20), $e_{c}^{*}$ is the optimal green level considering the uncertainty when the manufacturer decides to share the green cost as $t$. As in Proposition 1, the optimal green input level $e_{c}^{*}$ determined by the supplier decreases with the increase in the green cost coefficient $\mu$. Moreover, it increases with the increase in the green feasibility factor $\theta$, which is not elaborated and proved in detail here.

Proposition 2. In the case of the supplier's and the manufacturer's cooperative green investment:

(i) In the case of cooperative green investment, the greenness $e_{c}^{*}$ of products determined by the supplier is higher than that in the case of single supplier's green investment.

(ii) The greenness $e_{c}^{*}$ with a cooperative increases with the increase in the manufacturers' share $t$ of green products.

(iii) In the case of a cooperative green investment, the green feasibility threshold value of the supplier's green investment is lower than that of the single supplier's green investment. Therefore, the supplier's choice space for a green investment is larger under the cooperative green situation.

Proof

(i) Firstly, it is seen that $\left(\theta\left(a-c_{1}-c_{2}\right) /\right.$ $4 \mu-\theta)<\left(\theta\left(a-c_{1}-c_{2}\right) / 4(1-t) \mu-\theta\right)$ by comparing equation (11) with equation (20) because $0<t<1$. That is, in the case of cooperative, the greenness of a product determined by the supplier is higher than that in the case of a single supplier investment. When the manufacturer takes part in the green investment in intermediate components, the supplier is enthusiastic to carry out more green investment.

(ii) Secondly, in equation (20), we use the optimal green level $e_{c}^{*}$ to derive the manufacturer's green share $t$, we can get the result $\left(\partial e_{c}^{*} / \partial t\right)=\left(4 \mu \theta\left(a-c_{1}-c_{2}\right) /[4(1-t) \mu-\theta]^{2}\right)$, because $a>c_{1}+c_{2}$, and $\left(\partial e_{c}^{*} / \partial t\right)>0$ is calculated. That is to say, $e_{c}^{*}$ is the increasing function of $t$, which increases with the increase in share $t$. It is understood that as the manufacturer's share of the green investment in intermediate components increases, the risk of the supplier will be reduced, and the efforts for green investment will be increased.

(iii) Finally, it is similar to the case of the single supplier's green investment, that in the case of cooperative green, when the green product is uncertain, the supplier will only carry out the green investment if the profit of the green product is greater than that of no green investment. In other words, the condition $\prod_{s}(e) \geq \prod_{s}^{N}$, must be satisfied. That is to say, the following inequality must be satisfied:

$$
\theta \cdot \frac{\left(a-c_{1}-c_{2}+e\right)^{2}}{8}-\frac{1}{2}(1-t) \mu e^{2} \geq \frac{\left(a-c_{1}-c_{2}\right)^{2}}{8} .
$$

By substituting formula (20) into equation (21), the inequality can be rewritten as 


$$
\begin{aligned}
\theta \bullet & \frac{\left[a-c_{1}-c_{2}+\left(\theta\left(a-c_{1}-c_{2}\right) / 4(1-t) \mu-\theta\right)\right]^{2}}{8} \\
& -\frac{1}{2}(1-t) \mu\left[\frac{\theta\left(a-c_{1}-c_{2}\right)}{4(1-t) \mu-\theta}\right]^{2} \geq \frac{\left(a-c_{1}-c_{2}\right)^{2}}{8} .
\end{aligned}
$$

The following result can be obtained by simplifying inequality (22):

$$
\theta \geq \frac{4 \mu(1-t)}{4 \mu(1-t)+1}
$$

Let $\Phi=(4 \mu(1-t) / 4 \mu(1-t)+1)$, where $\Phi$ is the green feasibility threshold value of the product in the green cooperative case. Only when the green feasibility factor $\theta \geq \emptyset$, the supplier's green investment in the product will occur.

Comparing inequality (14) and inequality (23), it is easy to find that $(4 \mu(1-t) /(4 \mu(1-t)+1))<(4 \mu /(4 \mu+1))$ and $\omega<\xi$ because $0<t<1$. Because the supplier's selection range of green feasibility factors is $[4 \mu /(4 \mu+1), 1]$ in the case of a single supplier's green investment, and the supplier's selection range of green feasibility factors is $[4 \mu(1-t) /(4 \mu(1-t)+1), 1]$ in the case of cooperative green, as a result, the supplier's green feasibility threshold value in the case of a cooperative green is lower than that of the case of a single supplier. The supplier has more choice space for green investment in the case of a cooperative. For example, when the green feasibility factor of the green supply chain is in the range of $[\omega, \xi]$, the feasibility factor $\theta$ does not reach the threshold value $\xi$ because $\theta<\xi$ in the case of a single supplier. At this time, the expected revenue of the supplier from a green investment is negative, and the supplier will reject the green investment in the process of decision-making. However, the feasibility factor $\theta$ can reach the threshold value $\xi$ because $\theta>\omega$ in the case of green cooperative. At this time, the expected revenue of the supplier from the green investment is positive, and the supplier will accept the green investment in the process of decision-making.

It is understood that when the manufacturer shares the green investment in intermediate components, the minimum capital required for green products will be reduced, the supplier is more likely to make green investment.

\section{Proposition 3}

(i) The share of the manufacturer's green cost decreases with the increase in supplier's green cost coefficient.

(ii) The share of the manufacturer's green cost decreases with increase in the green feasibility factor.

\section{Proof}

(i) First, the goal of the decision-making process of the manufacturer is to maximize its own profits in the case of green cooperative. Substituting equations (15) and (17) into equation (5), the manufacturer's revenue function can be rewritten as follows:

$$
\prod_{m}=\frac{\left(a-c_{1}-c_{2}+e\right)^{2}}{16}-\frac{1}{2} t \mu e^{2}
$$

Substituting equation (20) into equation (24), the manufacturer's revenue function can be rewritten as follows:

$$
\begin{aligned}
\prod_{m}= & \frac{\left[a-c_{1}-c_{2}+\left(\theta\left(a-c_{1}-c_{2}\right) / 4(1-t) \mu-\theta\right)\right]^{2}}{16} \\
& -\frac{1}{2} t \mu\left[\frac{\theta\left(a-c_{1}-c_{2}\right)}{4(1-t) \mu-\theta}\right]^{2} .
\end{aligned}
$$

(i) In equation (25), we derive the manufacturer's revenue function $\prod_{m}$ to the share $t$. Let $\left(\partial \prod_{m} / \partial t\right)=0$, which allows to calculate out the green cost share of the manufacturer's profit maximization as follows:

$$
t^{*}=\frac{4 \mu(1-\theta)+\theta^{2}}{4 \mu(1+\theta)} .
$$

(ii) In equation (26), we derive the supplier's green cost coefficient $\mu$, and we obtain the following result:

$$
\frac{\partial t^{*}}{\partial \mu}=-\frac{\theta^{2}}{4(1+\theta)}<0
$$

(iii) From equation (27), it can be seen that the green cost share of the manufacturer is a decreasing function of the supplier's green cost coefficient. That is, with the increase in the supplier's green cost coefficient, the cost and risk of the manufacturer's green cost will be increased, and the enthusiasm of the manufacturer for an investment will be reduced.

(i) Secondly, in equation (26), we derive the green feasibility factor $\theta$ and can obtain the following result:

$$
\frac{\partial t^{*}}{\partial \theta}=\frac{(\theta / 2 \mu)+\left(\theta^{2} / 4 \mu\right)-2}{(1+\theta)^{2}}
$$

(ii) In equation (28), $\theta$ is in the range $[0,1]$, so it can be proven that the range of $\mu$ is $\mu>(1 / 2)$ in this green supply chain model. We will prove it in the following way:

(iii) In the process of green products, the revenue of the whole green supply chain is as follows:

$$
\prod_{T}=\prod_{s}+\prod_{m}=q\left(a-q-c_{1}-c_{2}+e\right)-\frac{1}{2} \mu e^{2} .
$$

(iv) We can get the function of maximizing the revenue of the whole green supply chain through an optimization solution as follows: 


$$
\prod_{T}^{*}(e)=\frac{\left(a-c_{1}-c_{2}+e\right)^{2}}{4}-\frac{1}{2} \mu e^{2} .
$$

(v) Because the marginal return rate of the green supply chain's input is decreasing, that is to say, it must meet the following condition:

$$
\frac{\partial \prod_{T}^{* 2}(e)}{\partial e^{2}}=\frac{1}{2}-\mu<0 .
$$

It is easy to obtain $\mu>(1 / 2)$ from inequality (31). In equation (28), because $\theta \in[0,1], \mu>(1 / 2)$, it is to get the result $\left(\partial t^{*} / \partial \theta\right)<0$ in equation (28), thus proving the conclusion.

$\left(\partial t^{*} / \partial \theta\right)<0$ means that the manufacturer's share of green costs decreases with the increase in the green feasibility factor and vice versa. This result is a bit unexpected, but it can be explained. If the feasibility factor of green products is high and the uncertainty is small, the supplier itself will have a strong enthusiasm to invest in green products, whereas the manufacturer shall not need to share the cost of the green products. If the feasibility factor of the green product is reduced, the supplier will reduce the green investment. In extreme cases, if the feasibility factor of green product is lower than the threshold value $4 \mu /(4 \mu+1)$, the supplier will reject the green investment. Therefore, the manufacturer should increase their share of green costs to encourage the supplier to carry out green investments when the feasibility factor of the green product is reduced. Otherwise, the benefits of the green product in the whole supply chain will be reduced.

In the result, we find that the green uncertainty will affect the investment level of the supplier and the investment share proportion of the manufacturer. With the increase of green feasibility, the supplier will make more green investment, and the share proportion of green investment undertaken by the manufacturer will be reduced .

\section{Numerical Analysis}

(1) In order to explain the relationship between the supplier's optimal green input level and the cost coefficient, we let $\theta=0.3, a=1, c_{1}=c_{2}=0.2$ and we take step length 0.1 in the range of $\mu \in[1,5]$. It can be seen from Figure 3 that the optimal green input level of the supplier decreases with the increase in supplier's cost coefficient.

(2) In order to explain the relationship between the optimal green level and the green feasibility factor and to compare the green level of the supplier under the condition of single green and cooperative green, we let $c_{1}=c_{2}=0.2, t=0.1$, and we take step length 0.1 in the range $\theta \in[0,1]$. It can be seen from Figure 4 that the green level of the supplier increases with the increase in the green feasibility factor both in the case of a single supplier and a cooperative. The green level of the supplier in the case of a cooperative is always higher than that in the case of single supplier.

(3) In order to explain the difference of the optional choice space between the case of a single supplier and the case of a cooperative, we take the step length 0.1 in the range $\mu \in[1,5]$ according equation (14) and equation (23). As can be seen in Figure 5, the critical threshold of the in the case of a single supplier is higher than in the case of a cooperative. The optional choice space $S$ in the case of a single supplier is smaller than that in the case of a cooperative (i.e., C). The blue area is the extra choice space obtained as the difference of the choice space of a cooperative minus the choice space of a single supplier case.

(4) In order to explain the relationship between the optimal green input level and the share of the manufacturer in the case of a cooperative, we let $\mu=1, a=1, c_{1}=c_{2}=0.2$, and $\theta=0.3$. In equation (20), we note that it must satisfy the condition $4(1-t) \mu-\theta>0$, thus satisfying $t<((4 \mu-\theta) / 4 \mu)$, that is, the range of $t$ is $[0,0.9]$. We take 0.1 as step in order to obtain figure. As seen from Figure 6, the optimal green input level increases with increase in the manufacturer's share of green cost.

(5) In order to explain the relationship between the manufacturer's share of green costs and the supplier's green cost coefficient, we let $\theta=0.3$ and we take step 0.1 in the range $\mu \in[1,5]$ according equation (26). It can be seen from Figure 7 that the manufacturer's share of green costs decreases with the increase in the supplier's green cost coefficient.

(6) In order to explain the relationship between the manufacturer's share of green cost and the green feasibility factor, we let $\mu=1$ and we take step 0.1 in the range $\theta \in[0,1]$ according to equation (26). It can be seen from Figure 8 that the manufacturer's share of green costs decreases with the increase in the green feasibility factor.

\section{Results and Discussion}

This paper studies the uncertainty of an environmental investment in a green supply chain. By constructing a Stackelberg model, we obtained the following results:

(i) In this paper, the green uncertainty factor is added into the environmental investment decision in a green supply chain. It is found that this uncertainty factor has an important impact on the environmental investment. Although Zhang et al. considered the impact of different channel strategies (single channel or dual-channel) on the environmental investment decision-making in a green supply chain, uncertainty was not taken into account. Furthermore, we found the impact of green uncertainty factors was ignored in the previous literature. 


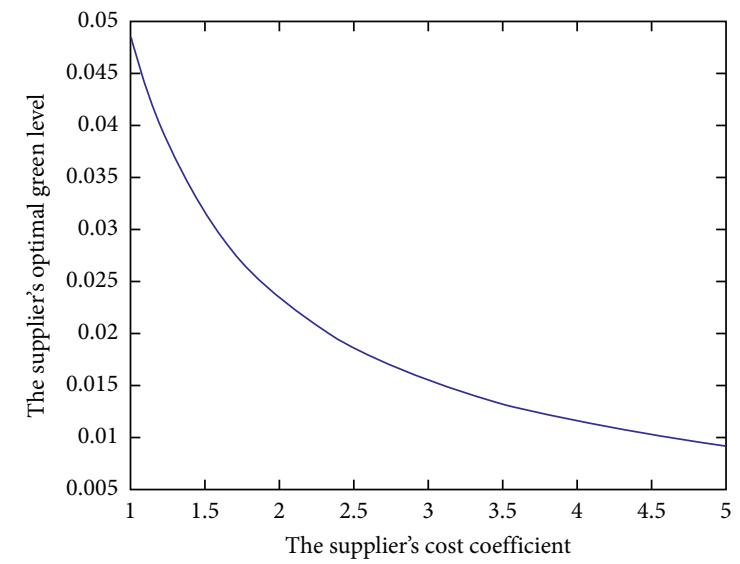

FIgURE 3: The relationship between the supplier's optimal green input level and the cost coefficient.



FIGURE 4: Comparing the green level of the supplier in the cases of a single supplier and a cooperative.

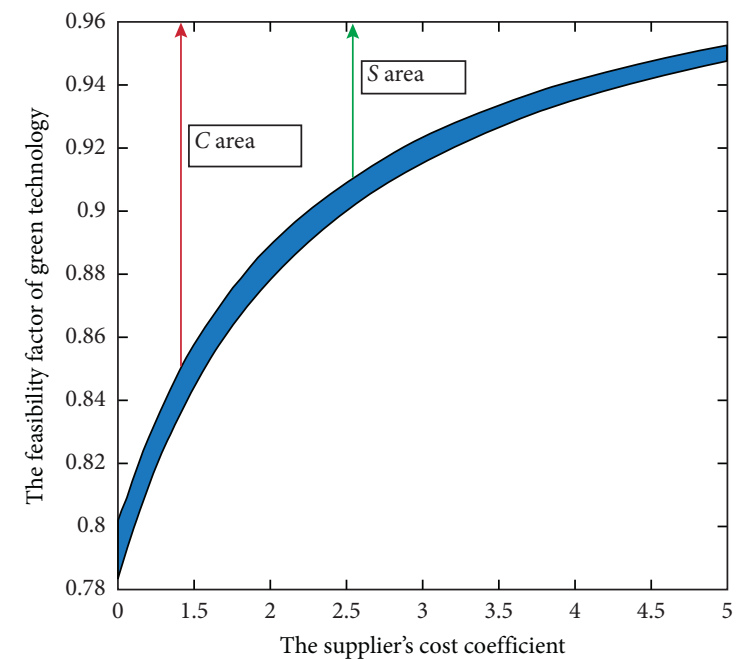

Figure 5: Comparing the choice space.

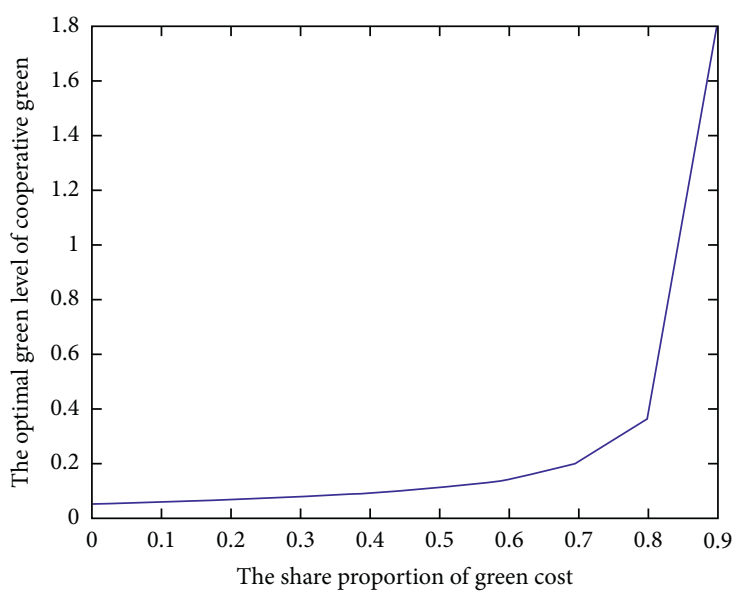

FIgURE 6: The relationship between the optimal green input level and the share of the manufacturer's green cost in the case of a cooperative.

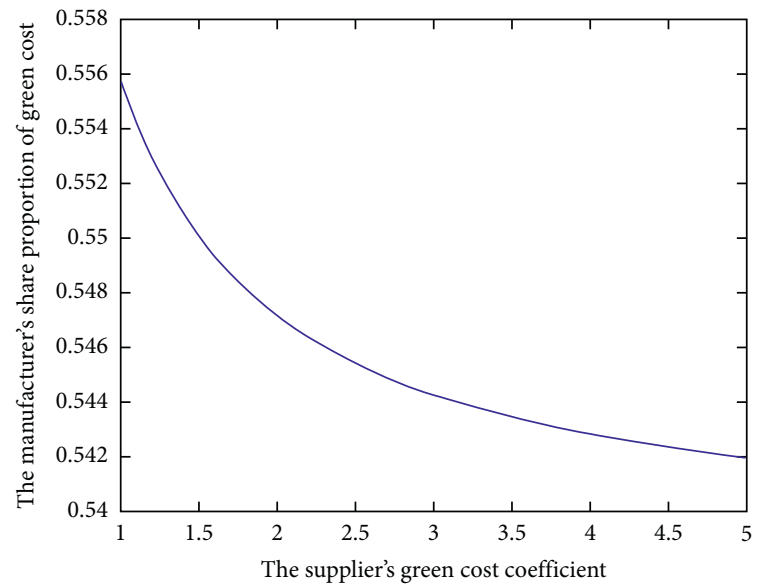

FIGURE 7: The relationship between the manufacturer's share of green cost and the supplier's green cost coefficient.

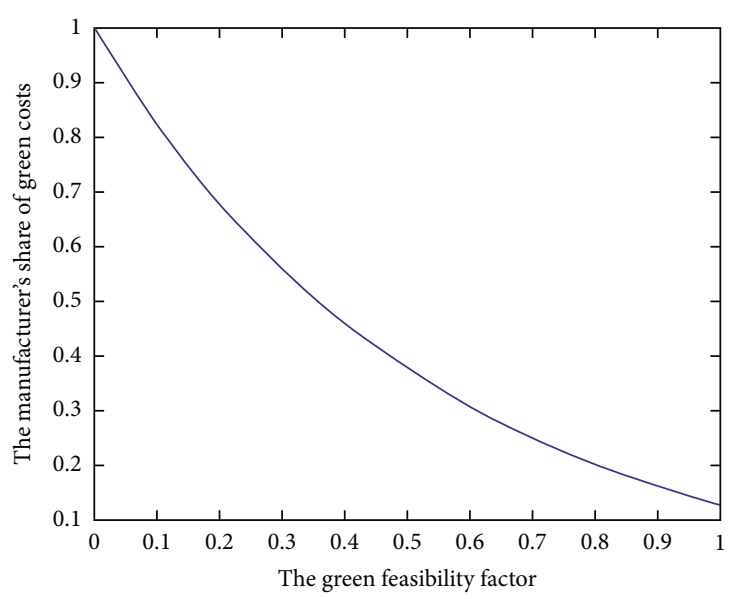

FIGURE 8: The relationship between the manufacturer's share of green cost and the green feasibility factor. 
(ii) In the case of a single supplier's green investment in intermediate components, the optimal green investment level of the supplier decreases with the increase in the green cost coefficient and increases with the increase in the green feasibility factor. Only when the green feasibility factor is higher than a certain threshold value can the supplier carry out a green investment. The possible reason is that, in the case of the single supplier's green investment, the supplier needs to consider the cost and risk factors for the green investment. The increase in the green cost coefficient will directly increase its cost, while the reduction of the green feasibility factor will increase the risk of its greening. Both of these can, in contrast, lead to the decrease in the supplier's return on the green investment and finally reduce their investment enthusiasm.

(iii) In the case where the supplier and the manufacturer jointly carry out the green investment, the optimal green investment level of the supplier increases with the manufacturer's share of the green investment. The greenness of the products in this cooperative is higher than in the case of single supplier. Also, the choice space of the supplier for the green investment is also larger. The possible reason is that the participation of the manufacturer will reduce the cost and risk of the supplier's green investment. This shall reduce the threshold of the supplier's green investment and improve the supplier's choice space for the green investment, overall improving the supplier's enthusiasm for a green investment.

(iv) The manufacturer's share of the green cost decreases with the increase in the supplier's green cost coefficient and increases with the decrease in the green feasibility factor. Consequently, the increase in the supplier's green cost coefficient will reduce the manufacturer's cost share, because the increase in the cost coefficient will increase the cost of the manufacturer's participation in the green investment. It seems unreasonable that the decrease in the green feasibility factor will lead to the increase in the manufacturer's cost share. One possible explanation is that the decrease in the green feasibility factor of the intermediate component means that the uncertainty of the green factors increases. To begin with, the supplier may not be willing to make a green investment, which will affect the income of the whole supply chain. As a response, the manufacturer should increase the share of the green cost and invest more in the greenness of the intermediate components' in order to encourage the supplier to make the green investment.

\section{Conclusions, Managerial Implications, Limitations, and Future Research}

8.1. Conclusions. Through this study of decision-making for an environmental investment in a supply chain, in the presence of uncertainty of green products, it is found that the green uncertainty has an important impact on the green investment level of the supplier and the share of the green investment undertaken by the manufacturer. To better demonstrate the research contribution of this article, here we will answer the questions raised above:

(i) What is the impact of supplier's green cost coefficient on the manufacturer's share of green cost and the supplier's input?

With the increase in the supplier's green cost coefficient, the supplier will reduce the green investment and the manufacturer will reduce the green share of costs.

(ii) What is the impact of product uncertainty on product greenness and green investment of the manufacturer and the supplier?

With the green uncertainty of intermediate components decreases and the green feasibility factor increases, the supplier will increase the greenness of intermediate components and increase the green investment, and the manufacturer will reduce the share of green costs.

(iii) What is the impact of the manufacturer's share of green cost on product greenness and the supplier's choice space?

The increase in the manufacturer's share of green cost will promote the supplier to increase the greenness of intermediate components and increase its green investment, and it will increase the supplier's optional choice space for the green investment. Considering the case when the manufacturer and the supplier are jointly making the green investment, the threshold value of the green input of the supply chain members (i.e., the manufacturer and the supplier) is lower. This allows the supply chain members to have more choice space. At the same time, the environmental effect in the case of this green cooperative is higher than that in the case of the single supplier.

8.2. Managerial Implications. Since there is little literature introducing the uncertainty into decision-making research with respect to the environmental investments in a green supply chain, this study attempts to fill in this research gap. We explore the impact of green uncertainty on investment, which can provide a reference for the manufacturer or the retailer in a green supply chain in adopting new strategies. Firstly, with the increase in the green cost coefficient of the supplier's intermediate components, both the supplier and the manufacturer will reduce the green investment. Therefore, in order to improve the greenness of products, the supplier should increase its green technology investment and reduce its green cost coefficient. Secondly, with the decrease in uncertainty and the increase in the green technology feasibility factor, the supplier should be more willing to increase the green investment in intermediate 
components, and the manufacturer could rely more on the supplier for green products. The manufacturer can reduce the uncertainty of green products and encourage the suppliers to increase green investment by adopting various measures such as technology prediction and product demand prediction. Thirdly, since the increase in the manufacturer's share of green costs will promote the supplier to increase the greenness of intermediate components and reduce the risk for the supplier, it is an important means for the manufacturer to increase their share of green cost in the cooperation process, so as to encourage the supplier's green investment. Lastly, the manufacturers' participation in a green investment can reduce the level of the green investment in a supply chain and expand the feasibility range of the green investment for the supplier, which makes it more possible for the supplier to invest in a green technology that could have higher uncertainty. Therefore, the participation of the manufacturer in the process of investing in green products is particularly important.

8.3. Limitations and Future Research. There are several limitations to this paper, which may be worth further exploring. Firstly, we have studied the sequential green decision-making of a manufacturer and a supplier under the conditions of uncertainty. However, we did not investigate the coordination problem of the overall revenue maximization of the green supply chain, which is an important issue to be studied in the future. Secondly, in order to simplify the analysis, this paper only considers a twoechelon green supply chain composed of one manufacturer and one supplier and does not consider the supply chain composed of multiple suppliers and one manufacturer. In fact, there may be multiple participants that could affect the green decision of all supply chain parties. Thirdly, in the process of considering the impact of green uncertainty on the decision of supply chain members, this paper ignores that the green input of supply chain may lead to the change of consumer demand, which in turn affects the green input decision of supply chain. For this reason, future research should consider the green uncertainty's influence on the coordination of the supply chain and add factors such as consumer demand and multiple participants in green supply chain.

\section{Data Availability}

The data used to support the findings of this study are available from the corresponding author upon request.

\section{Conflicts of Interest}

The authors declare that they have no conflicts of interest.

\section{Authors' Contributions}

Shaobo Wu conceptualized the study. Xun Yao wrote the original study. Guangdong $\mathrm{Wu}$ reviewed and edited the article.

\section{Acknowledgments}

This work was supported by the National Natural Science Foundation of China (Nos. 71972018 and 71561009), the project of Chengdu Soft Science Research "Research on the construction of Chengdu emerging industry innovation ecosystem and its collaborative development mechanism" (No. 2020-RK00-00278-ZF), the project of the Ministry of Education's Humanity and Social Sciences Research "Research on the process mechanism, operation mechanism and management strategy of collaborative innovation of high tech industry innovation ecosystem" (No. 17YJA630110), and the project of the Ministry of Education's Humanity and Social Sciences Research "Research on the evolution and early warning mechanism of uncertain network public opinions" (No. 19YJAZH044).

\section{References}

[1] X. Xu, Z. Xu, L. Chen, and C. Li, "How does industrial waste gas emission affect health care expenditure in different regions of China: an application of bayesian quantile regression," International Journal of Environmental Research and Public Health, vol. 16, no. 15, pp. 2748-48, 2019.

[2] Q. Zhu, J. Sarkis, and K.-h. Lai, "Institutional-based antecedents and performance outcomes of internal and external green supply chain management practices," Journal of Purchasing and Supply Management, vol. 19, no. 2, pp. 106-117, 2013.

[3] Z. Miao, T. Baležentis, S. Shao, and D. Chang, "Energy use, industrial soot and vehicle exhaust pollution-China's regional air pollution recognition, performance decomposition and governance," Energy Economics, vol. 83, pp. 501-514, 2019.

[4] X. Xu, L. Zhang, L. Chen, and C. Liu, "The role of soil N2O emissions in agricultural green total factor productivity: an empirical study from China around 2006 when agricultural tax was abolished," Agriculture, vol. 10, no. 5, p. 150, 2020.

[5] W. M. Cohen and S. Klepper, "Firm size and the nature of innovation within industries: the case of process and product R\&D," The Review of Economics and Statistics, vol. 78, no. 2, p. 232, 1996.

[6] Q. Zhu, J. Sarkis, and K.-h. Lai, "Examining the effects of green supply chain management practices and their mediations on performance improvements," International Journal of Production Research, vol. 50, no. 5, pp. 1377-1394, 2012.

[7] A. A. Hervani, M. M. Helms, and J. Sarkis, "Performance measurement for green supply chain management," Benchmarking: An International Journal, vol. 12, no. 4, pp. 330-353, 2005.

[8] S. Barari, G. Agarwal, W. J. Chris, B. Mahanty, and M. K. Tiwari, "A decision framework for the analysis of green supply chain contracts: an evolutionary game approach," Expert Systems with Applications, vol. 39, no. 3, pp. 29652976, 2012.

[9] J. Cao and X. Zhang, "Coordination strategy of green supply chain under the free market mechanism," Energy Procedia, vol. 36, pp. 1130-1137, 2013.

[10] A. Hafezalkotob, "Competition of two green and regular supply chains under environmental protection and revenue seeking policies of government," Computers \& Industrial Engineering, vol. 82, pp. 103-114, 2015.

[11] R. Aydin, C. K. Kwong, and P. Ji, "Coordination of the closedloop supply chain for product line design with consideration 
of remanufactured products," Journal of Cleaner Production, vol. 114, pp. 286-298, 2016.

[12] D. Yang and T. Xiao, "Pricing and green level decisions of a green supply chain with governmental interventions under fuzzy uncertainties," Journal of Cleaner Production, vol. 149, pp. 1174-1187, 2017.

[13] W. Zhu and Y. He, "Green product design in supply chains under competition," European Journal of Operational Research, vol. 258, no. 1, pp. 165-180, 2017.

[14] M.-B. Jamali and M. R. Barzoki, "A game theoretic approach for green and non-green product pricing in chain-to-chain competitive sustainable and regular dual-channel supply chains," Journal of Cleaner Production, vol. 170, pp. 10291043, 2018.

[15] A. A. Taleizadeh, N. Alizadeh-Basban, and B. R. Sarker, "Coordinated contracts in a two-echelon green supply chain considering pricing strategy," Computers \& Industrial Engineering, vol. 124, pp. 249-275, 2018.

[16] N. M. Modak, D. K. Ghosh, S. Panda, and S. S. Sana, "Managing green house gas emission cost and pricing policies in a two-echelon supply chain," CIRP Journal of Manufacturing Science and Technology, vol. 20, pp. 1-11, 2018.

[17] Z. Hong and X. Guo, "Green product supply chain contracts considering environmental responsibilities," Omega, vol. 83, pp. 155-166, 2019.

[18] E. Cao and M. Yu, "Trade credit financing and coordination for an emission-dependent supply chain," Computers \& Industrial Engineering, vol. 119, pp. 50-62, 2018.

[19] H. Song and X. Gao, "Green supply chain game model and analysis under revenue-sharing contract," Journal of Cleaner Production, vol. 170, pp. 183-192, 2018.

[20] K. Dey and S. Saha, "Influence of procurement decisions in two-period green supply chain," Journal of Cleaner Production, vol. 190, pp. 388-402, 2018.

[21] Y. Liu and T. Xiao, "Pricing and collection rate decisions and reverse channel choice in a socially responsible supply chain with green consumers," IEEE Transactions on Engineering Management, vol. 67, pp. 1-13, 2020.

[22] I. E. Nielsen, S. Majumder, and S. Saha, "Exploring the intervention of intermediary in a green supply chain," Journal of Cleaner Production, vol. 233, pp. 1525-1544, 2019.

[23] K. Murali, M. K. Lim, and N. C. Petruzzi, "The effects of ecolabels and environmental regulation on green product development," Manufacturing \& Service Operations Management, vol. 21, no. 3, pp. 519-535, 2019.

[24] Y. Luo, Q. Wei, Q. Ling, and B. Huo, "Optimal decision in a green supply chain: bank financing or supplier financing," Journal of Cleaner Production, vol. 271, p. 122090, 2020.

[25] H. Kang, S. Y. Jung, and H. Lee, "The impact of Green Credit Policy on manufacturers' efforts to reduce suppliers' pollution," Journal of Cleaner Production, vol. 248, pp. 119-271, 2020.

[26] H. Zhang, W. Liu, and Z. Jia, "Green supply chain decision modeling under financial policy, with or without uniform government emission reduction policy," Managerial and Decision Economics, vol. 41, no. 5, pp. 1-17, 2020.

[27] X. Yuan, X. Zhang, and D. Zhang, "Research on the dynamics game model in a green supply chain:government subsidy strategies under the retailer's selling effort level," Complexity, vol. 2020, Article ID 3083761, 15 pages, 2020.

[28] F. Shahzad, J. Du, I. Khan et al., "Untangling the influence of organizational compatibility on green supply chain management efforts to boost organizational performance through information technology capabilities," Journal of Cleaner Production, vol. 266, p. 122029, 2020.

[29] M. Pakseresht, B. Shirazi, I. Mahdavi, and N. Mahdavi-Amiri, "Toward sustainable optimization with Stackelberg game between green product family and downstream supply chain," Sustainable Production and Consumption, vol. 23, p. 198, 2020.

[30] J. Wang, Q. Wan, and M. Yu, "Green supply chain network design considering chain-to-chain competition on price and carbon emission," Computers \& Industrial Engineering, vol. 145, no. 7, p. 106503, 2020.

[31] C. Zhang, Y. Wang, and P. Ma, "Optimal channel strategies in a supply chain under green manufacturer financial distress with advance payment discount," International Transactions in Operational Research, vol. 9, pp. 1-24, 2020.

[32] Y. Wang, R. Fan, L. Shen, and M. Jin, "Decisions and coordination of green e-commerce supply chain considering green manufacturer's fairness concerns," International Journal of Production Research, vol. 25, no. 5, pp. 1-19, 2020.

[33] S. Wu, S. Wen, and Q. Zhouea, "Coordination of store brand product's green supply chain based on negotiation," Sustainability, vol. 12, no. 9, pp. 1-26, 2020.

[34] M. Ghomi-Avili, R. Tavakkoli-Moghaddam, S. G. Jalali Naeini, and A. Jabbarzadeh, "Competitive green supply chain network design model considering inventory decisions under uncertainty: a real case of a filter company," International Journal of Production Research, vol. 12, no. 5, pp. 1-20, 2020.

[35] X. Xu, J. Hao, L. Yu, and Y. Deng, "Fuzzy optimal allocation model for task-resource assignment problem in a collaborative logistics network," IEEE Transactions on Fuzzy Systems, vol. 27, no. 5, pp. 1112-1125, 2019.

[36] G.-D. Wu and D.-Z. Tang, "Inter-organizational cooperative innovation of project-based supply chains under consideration of monitoring signals," International Journal of Simulation Modelling, vol. 14, no. 3, pp. 539-550, 2015.

[37] X. Xu, J. Hao, and Y. Zheng, "Multi-objective artificial bee colony algorithm for multi-stage resource leveling problem in sharing logistics network," Computers \& Industrial Engineering, vol. 142, no. 4, p. 106338, 2020.

[38] G.-D. Wu, "Project-based supply chain cooperative incentive based on reciprocity preference," International Journal of Simulation Modelling, vol. 13, no. 1, pp. 102-115, 2014.

[39] X. Xu, Z. Lin, and J. Zhu, "DVRP with limited supply and variable neighborhood region in refined oil distribution," Annals of Operations Research, vol. 9, no. 12, pp. 1-25, 2020. 